\title{
PERLUNYA PERENCANAAN BEKISTING UNTUK MEMBERIKAN BENTUK KONSTRUKSI DAN PENGHEMATAN BIAYA
}

\author{
Telly Rosdiyani' ${ }^{1}$ Fendi Fariyanto², Gunawan Noor ${ }^{3}$ \\ 1, 2, 3 Program Studi Teknik Sipil, Universitas Banten Jaya, Jl. Raya Ciwaru II No.73 Kota Serang, Banten \\ Email: tellyrosdiyani004@gmail.com \\ Email:fenditho@gmail.com \\ Email: gunawan.unbaja@gmail.com
}

\begin{abstract}
ABSTRAK
Bekisting merupakan sebuah konstruksi yang bersipat sementara mempunyai persyaratan yang harus terpenuhi yaitu kekuatan, bagaimana material bekisting tidak patah saat menerima beban yang bekerja, serta syarat kekakuan bagaimana material bekisting tidak mengalami perubahan bentuk atau deformasi yang berarti. Namun persyaratan tersebut kurang diperhatikan, beranggapan suatu pekerjaan yang mudah. Bekisting sebagai penunjang konstruksi yang tidak begitu penting dalam struktur sehingga anggapan ini dapat mengalami keruntuhan berakibat kerugian terhadap waktu, tenaga, uang serta nama perusahaan pelaksanaan pekerjaan. Untuk hal itu gedung Diskominfo yang terdiri dua lantai sudah tentunya diperlukan perencanaan bekisting untuk memberikan informasi apakah perencanaan awal pekerjaan konstruksi bekisting struktur balok lantai 2 sudah memenuhi syarat kekuatan, kekakuan dan stabilitas, serta sistim bekisting jenis apakah yang dapat digunakan pada gedung tersebut supaya layak fungsi memberikan bentuk konstruksi dapat penghematan biaya dalam pelaksanaan konstruksi. Dalam perencanaan ini memerlukan Data Primer dan data Skunder, data primer diperoleh secara langsung melakukan wawancara terhadap pihak terkait sedangkan data skunder berupa peta, spektek, time schedule, gambar serta Rencana Anggaran Biaya. Hasil yang didapatkan bahwa penggunaan pelat bondek untuk bekisting pelat lantai dapat menghemat waktu pelaksanaan akan tetapi plat bondek belum diketahui secara pasti tegangan ijin sedangkan penggunaan bekisting kayu sebagai bekisting pelat sangat terjamin keamanannya syarat kekuatan, kekakuan dan stabilitas. Perencanaan lebih efektif dengan melihat kebutuhan luas bekisting apabila kurang dari $6000 \mathrm{~m}^{2}$ sistim yang paling ekonomis adalah sistim bekisting tradisional.
\end{abstract}

Kata Kunci: Kotak Cetak, Kekakuan, Kekuatan, Stabilitas

\begin{abstract}
Formwork is a construction that has a temporary means of three requirements that must be fulfilled, namely strength, how the formwork material is not broken when receiving the burden of working and the stiffness of the condition how the formwork material does not undergo significant change or deformation. However, the three requirements are less concerned, assuming that the work is easy to do as a construction support that is not so important that it can experience a collapse resulting in losses to time, energy, money as well as the name of the company's work execution. For this, the building of Diskominfo consisting of two floors is certainly needed formwork planning to provide information whether the initial planning of the construction works of the 2nd floor structure of the building block is already qualified strength, stiffness and stability, whether in the review of construction of a 2-storey beam structure formwork meets the requirements of strength, rigidity and stability and what type of formwork system can be used in the building to be worthy of the function of providing construction and can cost savings in the implementation of construction. In this planning requires primary data and secondary data, the primary data is obtained directly in an interview with the relevant parties while the secondary data is the map, Spectek, time schedule, images and budget plan. The results obtained that the use of a Bondek plate for the floor plate formwork can save the time of execution but the Bondek plate is not known for certain voltage permits while the use of wood formwork as a formwork plate is highly assured of its security requirements strength, rigidity and stability. Planning is more effective by looking at the broad needs of formwork when less than $6000 \mathrm{~m} 2$ The most economical system is the traditional formwork system.
\end{abstract}

Keywords: Print Box, Stiffness, Strength, Stability 


\section{PENDAHULUAN}

Bekisting atau formwork dijadikan suatu sarana penunjang untuk membantu struktur beton menentukan bentuk dari konstruksi beton pada saat beton masih segar (Asyanto. 2010). Merupakan cetakan sementara menahan beton selama beton dituang, dan dapat dibongkar apabila beton yang telah dituangkan mencapai kekuatan yang cukup atau dianggap beton sudah mengeras.

Bekisting yang digunakan dalam struktur konstruksi haruslah memperhatikan beberpa aspek persyaratan yaitu kualitas bekisting, keamanan bagi konstruksi dan biaya pemakaian bekisting itu sendiri harus direncanakan seekonomis mungkin (Badan Standarisai Nasional. 2002). Namun dijumpai pelaksanaan konstruksi, sarana penunjang ini kurang diperhatikan dari beberapa aspek tadi, sehingga terjadi kegagalan formwork dengan ambruknya bekisting (Asiyanto. 2008).

Gedung Diskominfo terletak di jalan Jend. Sudirman No 25 taman K3 Ciceri Kota Serang terdiri dari dua gedung yaitu gedung command center yang terdiri dari 3 lantai dan gedung kominfo terdiri dari 2 lantai termasuk di dalamnya terdapat musola. Dalam pembangunan gedung ini memerlukan struktur bekisting balok dan plat lantai untuk itu bekisting yang dipergunakan harus memperhatikan beberapa aspek yang disaratkan supaya bekisting mempunyai fungsi dengan baik. Namun dalam data nota desain perencanaan tidak tercantum, maka kami tertarik untuk dapat menganalisa perencanaan bekisting pembangunan gedung Diskominfo tersebut dengan harapan dapat memandu masyarakat dalam perencanaan konstruksi bekisting jangan sampai ada pemasangan bekisting dianggap mudah sehingga kurang diperhatikan . Dikhawatirkan dapat mengalami keruntuhan mengingat harga satuan pekerjaan beton sangat mahal maka perananan bekisting dalam penunjang struktur bangunan haruslah kuat, kaku dan stabil. Dengan demikian kerugian terhadap waktu, tenaga, uang serta nama perusahaan pelaksanaan pekerjaan dapat diminimalkan.

Sebagai contoh kejadian Pierhead Proyek Tol Cawang-Kampung Melayu (Becakayu) pada tahun 2018, yang mengakibatkan korban kecelakaan pada pekerja, proyek jalan tol Becakayu sendiri merupakan proyek strategis Nasional memiliki panjang ruas 11 kilometer. Selain itu pula kejadian ambruk bekisting Pierhead Proyek Tol BORR seksi 3A pada tahun 2019, ambruknya bekisting terjadi saat dilakukan pengecoran dari truck mixer, namun dalam kejadian ini tidak ada korban jiwa. Akibat kegagalan formwork itulah, menyebabkan banyak kecelakaan pada saat beton segar di tempatkan, misalnya cedera, hilangkan nyawa, keruksakan harta benda dan bahkan penundaan konstruksi. Umumnya kejadian hal ini terjadi tak terduga satu bagian gagal maka mengakibatkan kelebihan beban dan struktur bekisting runtuh. Dengan beberapa gambaran disebutkan diatas maka diperlukannya perencanaan bekisting dengan baik dalam memberikan bentuk konstruksi serta penghematan biaya konstruksi, aman dan selamat. Dalam penelitian ini untuk dapat mengetahui bagaimana perencanaan awal pekerjaan konstruksi bekisting struktur balok dan plat lantai sudah memenuhi syarat kekuatan, kekakuan dan stabilitas,bagaimana perencanaan kaji ulang pekerjaan konstruksi bekisting struktur balok dan plat lantai sudah memenuhi syarat kekuatan, kekakuan dan stabilitas,serta bagaimana jenis dan sistim bekisting bagaimana yang cocok digunakan pada pelaksanaan pembangunan gedung komifo kota Serang

\section{METODOLOGI PENELITIAN}

\subsection{Lokasi Penelitian}

Lokasi penetapan penelitian pada Proyek pada pembangunan Gedung Diskominfo Kota Serang

\subsection{Kebutuhan Data}

Dalam Penelitian ini memerlukan data-data terdiri dari data observasi yang merupakan data diambil peneliti dengan melihat langsung situasi penelitian, Data primer merupakan data yang diperoleh secara langsung misalnya dengan melakukan wawancara dengan petugas terkait. Data skunder merupakan data yang diperoleh peneliti dari sumber yang sudah ada misalnya gambar perencanaan adalah gambar yang dihasilkan dari pemikiran dari para perencana sebagai imajinasi dari para perencanaan yang digunakan sebagai alat komunikasi dengan pemilik mengetahui sejauh mana bangunan yang direncanakan tersebut, memenuhi keinginan dan kebutuhannya, peta lokasi dan sebagainya. 


\section{DATA DAN PEMBAHASAN}

Data hasil pengamatan pekerjaan pembangunan gedung Diskominfo kota Serang untuk perncanaan bekisting kolom, balok dan plat lantai :

a. Perencanaan bekisting kolom, balok dan plat lantai

- Menentukan beban bekisting

- Menentukan metode bekisting

- Menentukan material plat bekisting

- Menentukan jenis penompang yang berdiri vertikal

b. Pelaksanaan pekerjaan bekisting kolom,balok dan plat lantai

- Pekerjaan pemasangan plat bekisting

- Pekerjaan pemasangan penompang yang berdiri vertikal

- Pekerjaan Pelepasan bekisting

Dari data tersebut dianalisa dengan pengecekkan terhadap syarat keamanan, kekakuan dan stabilitas. Dari data perencanaan sebelumnya perencanaan kekuatan bekisting Nota Desain tidak diketemukan sehingga penulis mencoba untuk meneliti kekuatan bekisting yang ada berupa plat baja bondek. Namun untuk kaji ulang perencanaan akan menggunakan bekisting konvensional berupa bahan papan kayu, balok kayu dan perencah (steger Werk) dengan peninjauan penelitian pada lantai 2 bangunan kominfo .

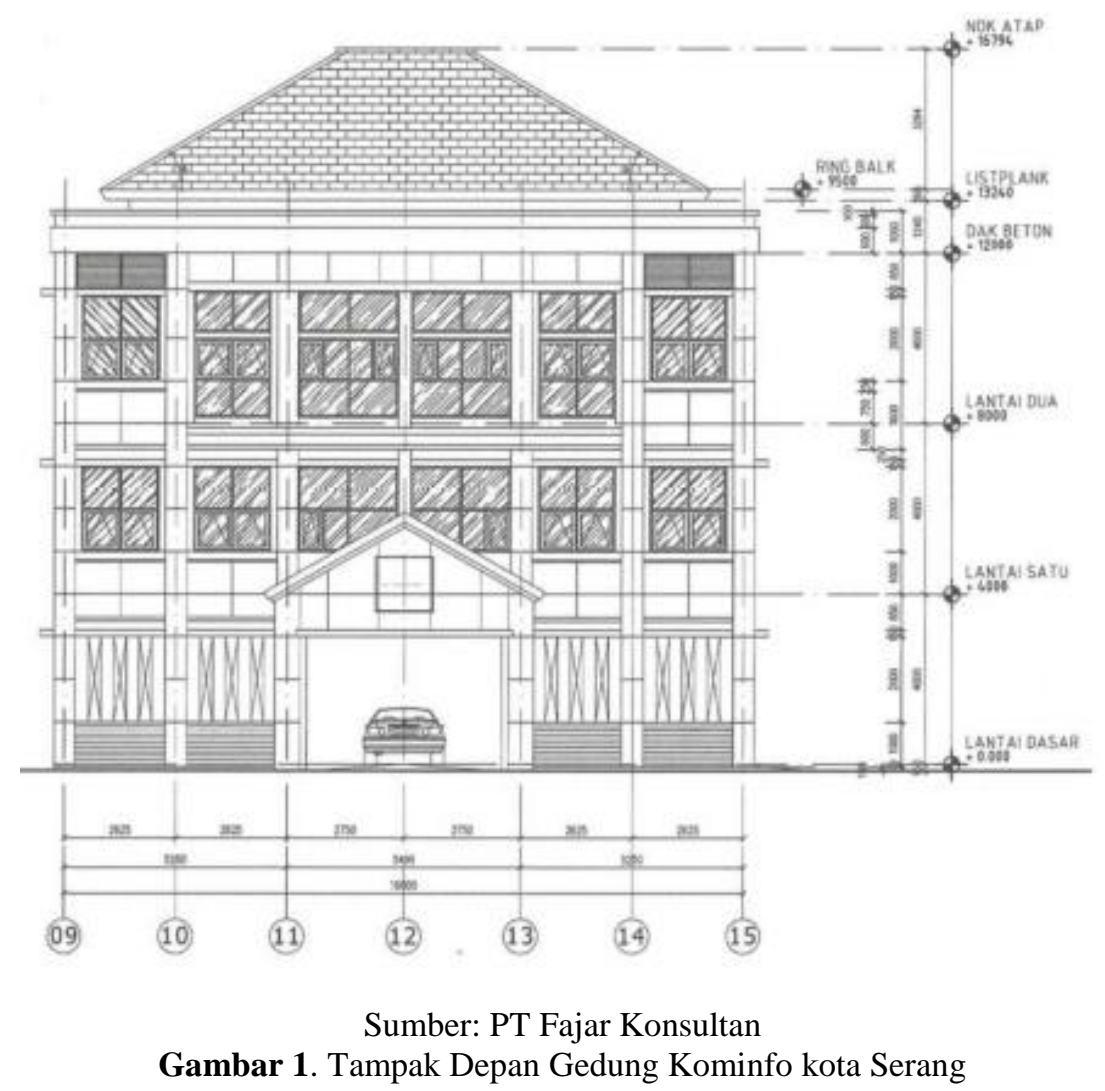




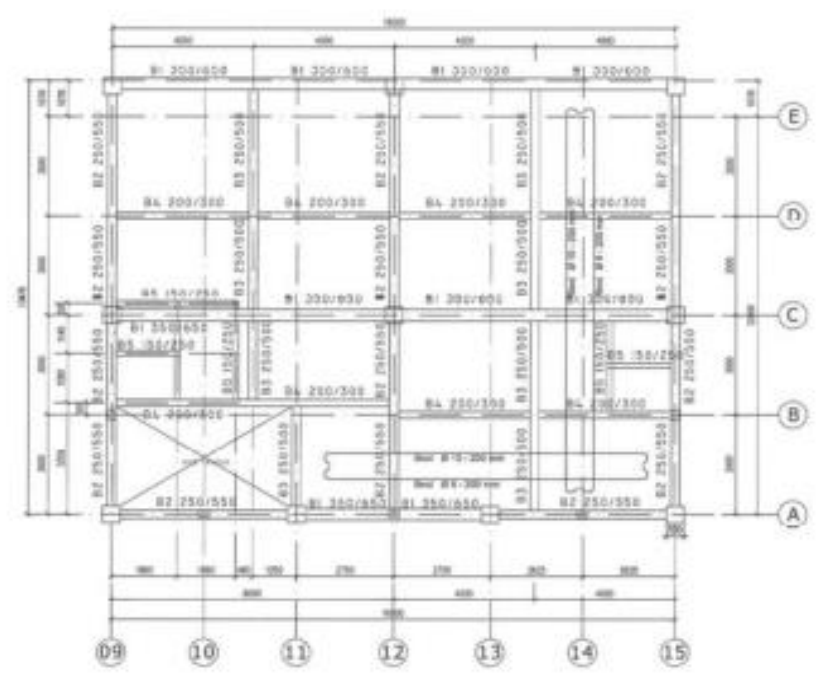

Gambar 2. Denah Rencana Balok Lantai 2 Gedung Kominfo Kota Serang

Berdasarkan Gambar 1 dan 2 berikut penjelasan ukuran balok dan plat lantai sebagai berikut:

Tebal Plat Lantai $=120 \mathrm{~mm}$

Dimensi Balok B1 $=350 \times 650 \mathrm{~mm}$

Dimensi Balok B2 $=250 \times 550 \mathrm{~mm}$

Dimensi Balok B3 $=250 \times 500 \mathrm{~mm}$

Dimensi Balok B4 $=200 \times 300 \mathrm{~mm}$

Dimensi Balok B5 = $150 \times 250 \mathrm{~mm}$
Dimensi Balok B6 $=300 \times 600 \mathrm{~mm}$

Dimensi Balok B7 $=250 \times 500 \mathrm{~mm}$

Dimensi Ring Balok $=100 \times 150 \mathrm{~mm}$

\subsection{Menghitung Beban - Beban}

Berdasarkan SNI 2847-2002,Bekisting konvensional menentukan terlebih dahulu bentang maksimal, atas dasar beban anak balok. Jarak penyangga dan dari beban penyangga dengan tenaga stempel atau tenaga penpusat yang diperkenankan kemudian mengakhiri bekisting kotak (Asroni. 2010). Untuk bekisting kotak ini umumnya digunakan material kayu papan tebal 19-21 mm, teripleks tebal $18-22 \mathrm{~mm}$, ukuran-ukuran plat lainnya 2,50 × 1,25 $\mathrm{m}^{2}$ atau 2,44 x 1,22 $\mathrm{m}^{2}$ dilengkapi maupun tidak dengan lapisan damar buatan yang dipoles serta papan-papan yang digabung.

Bekisting Plat Lantai: pada stempel-stempel khusus dipergunakan profil baja sebagai penyangga seperti gambar berikut ini:

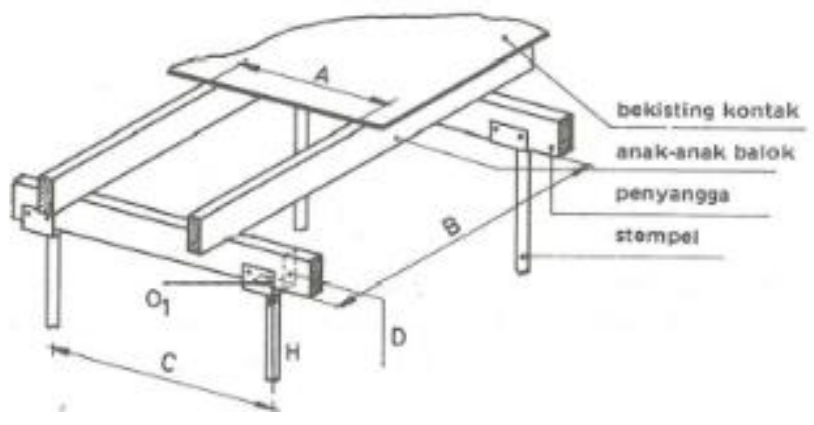

Gambar 3. Bagian-bagian dari konstruksi bekisting sebuah lantai 
Dimana :

$\mathrm{A}=$ Jarak as sampai as anak-anak balok

$\mathrm{B}=\mathrm{Jarak}$ as sampai as penyangga-penyangga

(kekuatan dan lentur anak-anak balok)

$01=$ Tekanan perletakan antara stempel dan penyangga
$\mathrm{C}=\mathrm{Jarak}$ as sampai as stempel-stempel

(kekuatan dan lenturan anak-anak balok)

$\mathrm{D}=$ Tegangan geser di dalam penyangga

$\mathrm{H}=$ Beban stempel/perencah yang diperkenankan

Rumus untuk balok-balok yang membentengi beberapa titik tumpu terdapat beban merata, beban merata membatasi diri sampai pada bobot sendiri dari bekisting pada tulangan yang ada. Bobot sendiri ini merupakan beban vertikal yang sipatnya berbeda-beda disesuaikan dengan medannya (PBI 1971 NI. 1971). Dengan hal inilah menimbulkan momen dan beban titik tumpu yang tidak menguntungkan dibanding beban yang berlanjut. Berikut rumus lenturan dalam sebuah medan.

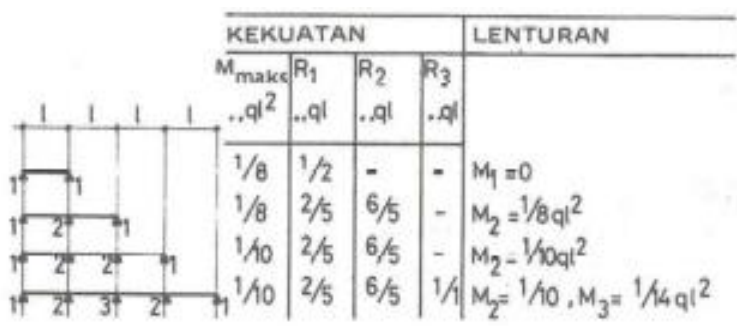

Gambar 4 Rumus Lenturan Dalam Sebuah Medan

Dengan rumus umum lenturan :

$\delta=\frac{5 . q l^{\wedge} 4}{384 . E . I}-\frac{(M s l . M s r) . l^{\wedge} 2}{16 . E . I}$

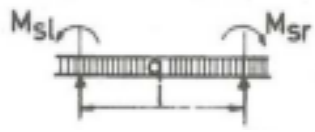

Dimana :

$\delta=$ Defleksi/ Tegangan lenturan

$\mathrm{ql}=$ Beban

Msr dan Msl = Momen suatu benda struktur

Dalam menentukan pembebanan pada anak balok, penyangga dan stempel, dapat bekerja dan reaksi perletakan. Perhitungan untuk sebuah penyangga, maka reaksi perletakan dari anak-anak balok dapat dibuah menjadi beban berlanjut. Adapun rumus yang digunakan sebagai berikut:

$$
\tau=\frac{D . s}{b . l}
$$

Dimana:

$\mathrm{D}=$ Gaya lintang $(\mathrm{KN})$

$\mathrm{S}=$ Statis Momen terhadap garis Netral; bx $1 / 2 \mathrm{~h} \times 1 / 4 \mathrm{~h}(\mathrm{~mm})$

$\mathrm{b}=$ Lebar sisi/Elemen yang ditinjau $(\mathrm{mm})$

$\mathrm{I}=$ Momen Inersia $\left(\mathrm{I}_{\mathrm{x}}\right) \quad(\mathrm{mm})$

Tegangan geser yang dihitung untuk penampang-penampang dengan bentuk persegi dengan tegangan perletakan (Wigbout. 1997). 


\section{Spekifikasi Plat Lantai Dan Bekisting}

Berdasarkan data gambar teknis perencanaan pembangunan gedung Kominfo Kota Serang lantai beton bertulang dengan tebal $120 \mathrm{~mm}$, tinggi tingkat $4000 \mathrm{~mm}$ material yang digunakan :

$\begin{array}{ll}\text { Bekisting kotak } & \text { : Kayu papan tebal } 20 \mathrm{~mm} \\ \text { Anak-anak Balok } & \text { : Kayu balok } 80 \times 150 \mathrm{~mm}^{2} \\ \text { Penyangga } & \text { : Kayu balok } 80 \times 150 \mathrm{~mm}^{2}\end{array}$

Sebagai beban-kerja pengganti muatan sementara $1,5 \mathrm{KN} / \mathrm{m}^{2}$ merupakan beban normal kayu papan kls A; $\mathrm{E}_{\text {kayu }}$ $=9000 \mathrm{~N} / \mathrm{mm}^{2}$ dengan lenturan yang diperkenankan 1/300 atau 0,0033 dari bentangan.

\begin{tabular}{lcc}
\multicolumn{3}{c}{ Tabel 1 Beban Yang Diperkenankan Stempel Skrup } \\
\hline No & $\begin{array}{c}\text { Beban Yang } \\
\text { Diperkenankan } \\
\text { (KN) }\end{array}$ & $\begin{array}{c}\text { Panjang } \\
(\mathrm{mm})\end{array}$ \\
\hline 1 & 9,0 & 3600 \\
2 & 11,0 & 3300 \\
3 & 13,5 & 3000 \\
4 & 17,0 & 2700 \\
5 & 20,0 & 2400 \\
6 & 23,0 & 2100 \\
\hline
\end{tabular}

Sumber: Wigbout Bekisting (Kotak Cetak),1997

Tabel 2. Tegangan Maksimum Yang Diperkenankan

\begin{tabular}{|c|c|c|c|}
\hline $\begin{array}{l}\text { Tegangan } \\
\text { dan } \\
\text { Elastisitas }\end{array}$ & $\begin{array}{c}\text { Kayu kelas kering II } \\
\text { dan III } \\
\left(\mathrm{N} / \mathrm{mm}^{2}\right)\end{array}$ & $\begin{array}{c}\text { Kayu kelas } \\
\text { kering IV ( x } 0,9 \\
\text { ( N/mm } \\
\left.\text { ( } \mathrm{mm}^{2}\right)\end{array}$ & $\begin{array}{c}\text { Kayu Bekisting } \\
\left(\mathrm{x} \frac{1}{0,7}\right) \\
\left(\mathrm{N} / \mathrm{mm}^{2}\right)\end{array}$ \\
\hline $\bar{\sigma}_{b}$ & 7,0 & 6,3 & $9,0^{1}$ \\
\hline$\sigma_{t}$ & 5,0 & 4,5 & 6,5 \\
\hline $\bar{\sigma}_{d} / /$ & 6,5 & 5,9 & 8,5 \\
\hline$\overline{\sigma_{d}} \perp$ & 2,0 & 1,8 & 2,5 \\
\hline$\overline{\mathrm{i}}$ & 1,0 & 0,9 & 1,3 \\
\hline $\mathbf{E} /$ & 10000 & 9000 & 9000 \\
\hline $\bar{E} \perp$ & 300 & 270 & 270 \\
\hline G/ & 500 & 450 & 450 \\
\hline $\mathbf{G} \perp$ & 40 & 36 & 36 \\
\hline
\end{tabular}

Sumber: Wigbout Bekisting (Kotak Cetak),1997

\subsection{Perhitungan Bekisting Kotak}

a. Momen Tahanan (per lebar $\left.=\mathrm{m}^{1}\right)$

$\mathrm{W}_{\mathrm{x}}$ per $\mathrm{m}^{\prime}=1 / 6 \cdot \mathrm{b} \cdot \mathrm{h}^{2}=66,7 \times 10^{3} \mathrm{~mm}^{3}$

b. Momen Inersia (per lebar $=\mathrm{m}^{1}$ )

Ix per m' $=1 / 12 \cdot$ b. $h^{3}=667 \times 10^{3} \mathrm{~mm}^{4}$

Beban Lantai

Bobot sendiri beton bertulang $\quad=0,12 \times 24=2,88 \mathrm{KN} / \mathrm{m}^{2}$

Beban sendiri bekisting $\quad=0,45 \times 1 / 0,7=0,64 \mathrm{KN} / \mathrm{m}^{2}$

Beban kerja/coran $\quad=1,50 \mathrm{KN} / \mathrm{m}^{2}$

Jumlah beban lantai $\quad=\mathbf{5 , 0 2} \times \mathbf{1 0}^{3} \mathrm{~N} / \mathbf{m m}^{2}$ jadi per $\mathbf{m}^{\prime} \mathbf{q}=\mathbf{5 , 0 2} \mathrm{N} / \mathbf{m m}$,

$\frac{M}{W} \leq \sigma$ jadi $\mathrm{M} \leq \sigma . \mathrm{W}$ 
$\mathrm{M}=1 / 10 . \mathrm{q} \cdot \mathrm{l}^{2} \leq \sigma . \mathrm{W}$ maka $1 \leq\left(10 \times 10 \times 66,7 \times 10^{3} \times 1 / 5,02\right)^{0,5}$

Jadi $1 \leq 1152 \mathrm{~mm}$

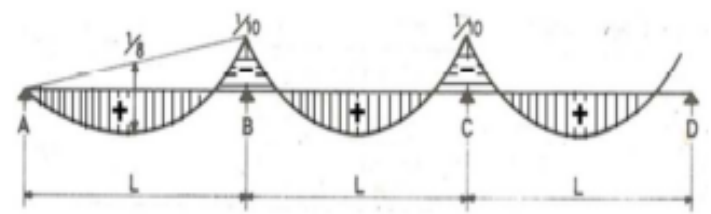

Gambar 5 Diagram Momen Lentur (BMD)

$\mathrm{F}_{\mathrm{AB}}=\frac{5}{384} \cdot \frac{q x l^{\wedge} 4}{E I}-\frac{1}{10} \cdot \mathrm{ql}^{2} \cdot \frac{l^{\wedge} 2}{16 E I}=0,00677 \frac{q l^{\wedge} 4}{E I} \leq 0,00331$ maka $1 \leq 836 \mathrm{~mm}$

Dari perhitungan diatas untuk memenuhi syarat kekuatan dan kekakuan dari bekisting kotak maka diambil jarak yang kecil, jadi jarak anak-anak balok sebesar $836 \mathrm{~mm}$.

Anak Balok:

a. Momen Tahanan

$\mathrm{W}_{\mathrm{x}}$ per $\mathrm{m}^{\prime}=1 / 6 . \mathrm{b} . \mathrm{h}^{2}=1 / 6.60 .150^{2}=225 \times 10^{3} \mathrm{~mm}^{3}$

b. Momen Inersia (per lebar $=\mathrm{m}^{1}$ )

Ix per $\mathrm{m}^{\prime}=1 / 12 \cdot \mathrm{b} \cdot \mathrm{h}^{3}=16,88 \times 10^{3} \mathrm{~mm}^{4}$

Beban Anak Balok

q anak balok $=$ Jarak aman $\mathrm{x}$ beban plat lantai $=836 \times 5,02 \times 10^{3}=4,2 \mathrm{~N} / \mathrm{mm}$ '

$\frac{M}{W} \leq \sigma$ jadi $\mathrm{M} \leq \sigma . \mathrm{W}$

1/8.q. $1^{2} \leq \sigma$. W maka $1 \leq\left(8 \times 9 \times 225 \times 10^{3} \times \frac{1}{4,2}\right)^{0,5}=1 \leq 1964 \mathrm{~mm}$

$\mathrm{F}_{\mathrm{AB}}=\frac{5}{384} \cdot \frac{q x l^{\wedge} 4}{E I}-\frac{1}{10} \cdot \mathrm{ql}^{2} \cdot \frac{l^{\wedge} 2}{16 E I}=(0,01302-0,00625) \frac{q x l^{\wedge} 4}{E I}=0,00677 \frac{q x l^{\wedge} 4}{E I}$ maka $1 \leq 2521 \mathrm{~mm}$ dari perhitungan diatas untuk memenuhi syarat kekuatan dari anak-anak balok maka diambil jarak yang kecil $=1964 \mathrm{~mm}$ pusat ke pusat

Penyangga

a. Momen Tahanan

$\mathrm{W}_{\mathrm{x}}$ per $\mathrm{m}^{\prime}=1 / 6 . \mathrm{b} \cdot \mathrm{h}^{2}=1 / 6 \cdot 60.150^{2}=225 \times 10^{3} \mathrm{~mm}^{3}$

b. Momen Inersia (per lebar $\left.=\mathrm{m}^{1}\right)$

Ix per $\mathrm{m}^{\prime}=1 / 12 \cdot \mathrm{b} \cdot \mathrm{h}^{3}=16,88 \times 10^{3} \mathrm{~mm}^{4}$

Beban anak balok

$\mathrm{q}$ anak balok $=$ Jarak aman $\mathrm{x}$ beban plat lantai $=1964 \times 5,02 \times 10^{3}=9,86 \mathrm{~N} / \mathrm{mm}^{\prime}$

Jika penyangga diibaratkan bertumpu pada 4 buah titik maka momen yang terjadi sebesar $1 / 10 \mathrm{x} \mathrm{q} \mathrm{x} 1^{2}$

$\frac{M}{W} \leq \sigma$ jadi $\mathrm{M} \leq \sigma . \mathrm{W}$ maka $1 \leq\left(10 \times 9 \times 225 \times 10^{3} \times 1 / 9,86\right)^{0,5}=1 \leq 1433 \mathrm{~mm}$

$\mathrm{F}_{\mathrm{AB}}=\frac{5}{384} \cdot \frac{q x l^{\wedge} 4}{E I}-\frac{1}{10} \cdot \mathrm{ql}^{2} \cdot \frac{l^{\wedge} 2}{16 E I}=0,00677 \frac{q x l^{\wedge} 4}{E I}=1 \leq 1897 \mathrm{~mm}$ dari perhitungan diatas untuk memenuhi syarat kekuatan dan kekakuan dari balok penyangga diambil jarak yang kecil jadi untuk sementara jarak ste,mpel $1433 \mathrm{~mm}$ pusat ke pusat

Stempel

Besar beban stempel : 
1 anak-anak balok x 1 penyangga $\mathrm{x}$ q plat lantai

$1964 \times 1433 \times 5,02 \times 10^{3}=14,13 \mathrm{KN}$ panjang stempel yang diperlukan adalah :

4000-120-20-150-150 = $3560 \mathrm{~mm}$ maka besar tegangan normal yang diperkenankan adalah:

Beban2 - $\left(\frac{1 \text { beban perlu-beban } 2}{1 \text { batang1-1 batang } 2}\right)($ beban $2-$ beban 1$)$

$=11-\left(\frac{3560-3300}{3600-3300}\right)(11-9)=9,27 \mathrm{KN}$

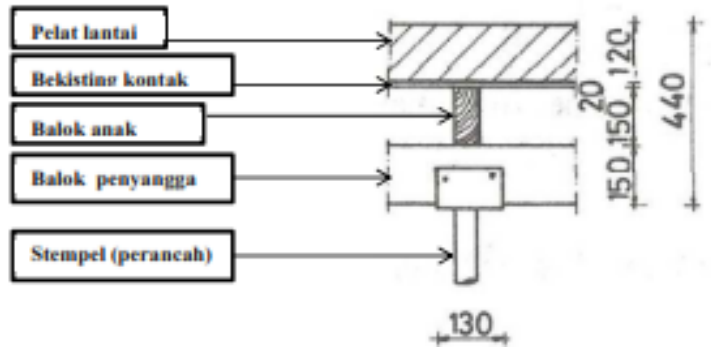

Gambar 6. Penampang Melintang Konstruksi Bekisting Lantai

Jarak Stempel $=\frac{\text { Besar tegangan normal yang diperkenankan }}{\text { Besar beban stempel }} \times 1$ penyangga

Jarak stempel $=\frac{9,27}{14,13} \times 1433=940 \mathrm{~mm}$ jadi jarak antar stempel adalah $940 \mathrm{~mm}$

\subsection{Kontrol Gaya Lintang dan Tekanan Letakan}

a. Gaya Lintang Penyangga

Gaya lintang yang paling besar terjadi di sisi stempel sebesar :

$\mathrm{D}=1 / 2 \times 14.13=7,07 \mathrm{KN}$; tegangan geser $=\tau=\frac{D . s}{b . l}$ maka diperoleh :

$\overline{\mathrm{D}}=1,3 \times 60 \times 16,88 \times 10^{6} \times \frac{1}{60 \times 75 \times 37,5}=7,802 \mathrm{KN}$ maka $\mathrm{D} \leq \mathrm{D}$ nilai yang diperkenankan lebih besar pada yang berlangsung maka aman (Gere-Timoshenko).Tekanan letakan antara stempel dan penyangga

Beban yang terjadi : 1 balok penyangga $\mathrm{x} 1$ sumple $\mathrm{x}$ Dx $1 / 2=6,53 \mathrm{KN}$

Beban yang terjadi : $1,964 \times 0,94 \times 7,07 \times 1 / 2=6,53 \mathrm{KN}$

Beban stempel $\quad: 2 \times 6,53=13,1 \mathrm{KN}$ pada panjang kepala stempel $130 \mathrm{~mm}$ dan lebar balok $60 \mathrm{~mm}$ hal ini akan mengarah pada suatu tekanan letakan sebesar :

$\frac{13,1 \times 10^{\wedge} 3}{130 \times 60}=1,68 \mathrm{~N} / \mathrm{mm}^{2}$ jadi tekanan letakan antara stempel dan penyangga aman.

\section{Begisting Balok}

Spesifikasi:

Ukuran balok 350 x $650 \mathrm{~mm}$; Tebal lantai $120 \mathrm{~mm}$; Balok as samapi as 4,0 m, bekisting kotak kayu $20 \mathrm{~mm}$; penjepit dan sekur kayu 20 x $90 \mathrm{~mm}^{2}$, konstruksi penampang kayu balok 60 x $150 \mathrm{~mm}^{2}$

\section{Kayu Papan}

Tinggi balok dan lantai $650 \mathrm{~mm}+120 \mathrm{~mm}=770 \mathrm{~mm}$ besar tekananan spesi maksimum papan samping $=0,77$ x $24=18,5 \mathrm{KN} / \mathrm{m}^{\prime}$ momen terbesar dalam kayu papan :

$\mathrm{M}=1 / 10$. q. $1^{2}=\sigma \times \overline{\mathrm{w}}$

$1 / 10.18,5.1^{2} \leq 10 \times 66,7 \times 10^{3}=1 \leq 600 \mathrm{~mm}$

$\mathrm{F}_{\mathrm{AB}}=\frac{5}{384} \cdot \frac{q x l^{\wedge} 4}{E I}-\frac{1}{10} \cdot \mathrm{ql}^{2} \cdot \frac{l^{\wedge} 2}{16 E I}=0,00677 \frac{q x l^{\wedge} 4}{E I} \leq 0,00331$ maka $1 \leq 542,6 \mathrm{~mm}$ sehingga besar jarak penjempit as sampai as $0,54 \mathrm{~m}$ 
Penjepit

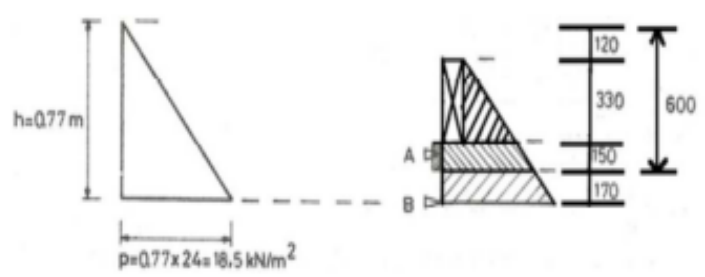

Gambar 7 Bagian-bagian konstruksi dari sebuah bekisting balok

$\mathrm{M}_{0}=1$ penjepit $\mathrm{x}$ lantai $\times \mathrm{BJ} \times 1 / 2 \times(600-(\mathrm{h} \text { lantai }+\mathrm{h} \text { balok }))^{2}+1$ penjepit $\mathrm{x}(600-\mathrm{h}$ lantai $+\mathrm{h}$ balok $\left.)\right) \times \mathrm{BJ} \times$ $1 / 6 \times\left(600-(\text { h lantai }+\mathrm{h} \text { balok })^{2 \mathrm{z}}\right.$

$\mathrm{M}_{0}=0,54 \times 0,12 \times 24000 \times 1 / 2 \times 0,33^{2}+0,54 \times 0,33 \times 2400 \times 1 / 6 \times 0,33^{2}=84,68+77,62=162,3 \mathrm{Nm}$

$\mathrm{Mv}=\mathrm{Wy} \times 1$ penjepit $\times 1 / 2 \times$ (h balok $+\mathrm{h}$ bekisting) $\times \mathrm{BJ} \times \mathrm{h}$ penjepit ${ }^{2}-1 / 2 \times \mathrm{M}_{0}$

$\mathrm{Mv}=0,06 \times 0,54 \times 1 / 2 \times(0,77+0,6) \times 24000 \times 0,17^{2}-1 / 2 \times 162,3=-65,8 \mathrm{Nm}=66 \mathrm{Nm}>\mathrm{My}=5 \overline{4} \times 10^{3} \mathrm{Nmm}$, jarak penjeit harus dikurangi hingga $54 / 66 \times 0,54=0,44 \mathrm{~m}$ jadi jarak penjepit sebesar $0,44 \mathrm{~m}$, kayu yang digunakan minim $=0,0033 \times 170=0,56 \mathrm{~mm}$ untuk keamanan papan digunakan kayu papan $20 \mathrm{~mm} \times 90 \mathrm{~mm}$.

Besar Beban setiap penjepit

1 penjepit $\mathrm{x}\left(\mathrm{h}\right.$ balok $\mathrm{x}$ h lantai $\mathrm{x} 1 / 2 \times \mathrm{h}^{1}$ balok $\left.^{2}\right)+\mathrm{BJ}$

$=0,44 \times\left(0,65 \times 0,12+1 / 2 \times 0,65^{2}\right) 24000=3054 \mathrm{~N}$

Momen dari beban sekeliling ujung kaki penjepit

1 penjepit $\mathrm{x}\left(1 / 2 \mathrm{xh}\right.$ balok $^{2} \mathrm{x}$ h lantai $\mathrm{x} 1 / 3 \times \mathrm{h}$ balok $\mathrm{x} \frac{1}{2} \mathrm{x}$ h balok $\left.^{2}\right)+\mathrm{BJ}$

$0,44 \times\left(1 / 2 \times 0,65^{2} \times 0,12 \times 1 / 3 \times 0,65 \times 1 / 2 \times 0,65^{2}\right) \times 24000=751 \mathrm{Nm}$

Momen ini sama besarnya dengan momen dari reaksi letakan terhadap kayu balok maka;

$\mathrm{R}_{\mathrm{a}}=\frac{751}{0,170+0,35 \times 0,15}=3375 \mathrm{~N}$ maka $\mathrm{R}_{\mathrm{b}}=3054-3375=-351 \mathrm{~N}$ sehinga Tegangan tekan antara penjepit $\sigma=$ $\frac{321}{20 \times 90}=0,178 \mathrm{~N} / \mathrm{mm}^{2}<\sigma \quad$ aman

Skur (penyokong /Support)

Besar tekanan horisontal spasi beton terhadap kayu balok penopang untuk setiap penjepit $3375 \mathrm{~N}$ jadi tekanan horisontal spasi beton terhadap kayu balok penopang per $\mathrm{m}^{\prime}=3375: 0,44=7670 \mathrm{~N}$; iy $=5,77 \mathrm{~mm}$; panjang tekuk $1 \mathrm{k}=544,5 \mathrm{~mm}$ maka $1 \mathrm{y}=94,4$ berdasarkan tabel Stempel kayu yang menerima beban.

Besar jarak sekur yang diperlukan adalah :

$\mathrm{F}_{\mathrm{k}}=2,38 \times 20 \times 90=4248 \mathrm{~N}$ besar jarak sekur $=0,43$, Besar tekanan yang diperkenankan untuk sekur terhadap kayu balok penompang sebesar : $F=2,5 \times 1 / 2 \times \sqrt{2} \times 20 \times 90=3182 \mathrm{~N}$ jarak yang seharusnya : $\frac{F}{\text { tekanan spasi beton }}=3182 / 6966=0,45 \mathrm{~m}$ maka jarak skur yang diambil adalah $0,43 \mathrm{~m}$.

Kayu Balok Penompang + Jarak Klos

Besar beban horisontal terhadap balok penompang $=7670 \mathrm{~N} / \mathrm{m}^{\prime}$ jarak sekur adalah 0,39 $\mathrm{m}$, momen maksimum perletakan yang terjadi dalam kayu balok sebesar:

$\mathrm{M}^{\mathrm{H}}=1 / 10 \times$ Beban horisontal terhadap balok penompang $\mathrm{x} 1_{\text {sekur }}{ }^{2}=299 \mathrm{Nm}$ terdapat sebuah tegangan sebesar $299 / 90=3,32 \mathrm{~N} / \mathrm{mm}^{2}$ sehingga beban vertikal sebesar 9,0 $-3,32=5,68 \mathrm{~N} / \mathrm{mm}^{2}$ sama dengan sebuah momen yang besarnya $5,68 \times 225=1278 \mathrm{Nm}$.

Besar beban vertikal

$\mathrm{q}=1 / 2 \times 1 \times(\mathrm{h}$ plat $\times \mathrm{BJ}+$ beban kerja + berat sendiri bekisting)

$\mathrm{q}=1 / 2 \times 4,00 \times(0,12 \times 24000+1500+1 / 0,7 \times 450) 10056 \mathrm{~N} / \mathrm{m}^{\prime}$

$\mathrm{M}_{\mathrm{v}}=1 / 10 \times \mathrm{q} \mathrm{x} \mathrm{l}^{2}=1,27 \mathrm{~m}$ jadi jarak maksimum klos adalah 1,27 di cek tekanan letakan : 
$\sigma=\frac{P}{A}$ dimana $\mathrm{P}=1,27 \times 7670=9741 \mathrm{~N}$ jadi $\sigma=1,08 \mathrm{~N} / \mathrm{mm}^{2}<\sigma \quad=====$ Aman

Dasar Balok (Perletakan balok), jarak maksimum pemikul anak balok adalah $520 \mathrm{~mm}$ dan pemikul (anak balok) sebesar $0,52 \mathrm{~m}$

\section{KESIMPULAN}

Penggunaan pelat bondek untuk bekisting pelat lantai dapat menghemat waktu pelaksanaan namun belum diketahui pasti secara pasti tegangan ijinnya sedangkan penggunaan kayu sebagai bekisting pelat terjamin karena sudah diketahui nilai tegangan ijinnya sehingga dapat terpenuhi stabilitasnya. Luas bekisting kurang dari $6000 \mathrm{~m}^{2}$ sistim paling ekonomis menggunakan bekisting tradisional.

\section{DAFTAR PUSTAKA}

Asyanto, Formwork for Concrete. Jakarta: UI Press, 2010.

Badan Standardisasai Nasional, "Tata cara perencanaan konstruksi kayu Indonesia.” 2002.

Asiyanto, Model Konstruksi Gedung Bertingkat. Jakarta: UI Press, 2008.

Asroni Ali, Balok dan Pelat Beton Bertulang. Yogyakarta: Graha Ilmu Yogyakarta, 2010.

PBI 1971 N.I. - 2, "Peraturan Beton Bertulang indonesia 1971 N.I. - 2," Jakarta Direktorat Penyelid. Masal. Bangunan, vol. 7, p. 130, 1971.

Wigbout, Bekisting(Kotak Cetak) Cetakan kedua,. Jakarta: Erlangga, 1997.

Gere-Timoshenko, Mekanika bahan jilid I edisi keempat. Jakarta: Erlangga. 